
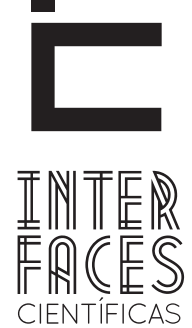

DIREITO

\title{
A VIOLÊNCIA SIMBÓLICA DE GÊNERO PROPAGADA PELA INDÚSTRIA CULTURAL E OS DIREITOS HUMANOS DAS MULHERES
}

Amanda Muniz Oliveira ${ }^{1}$
Rodolpho Alexandre Santos Melo Bastos

\section{RESUMO}

Este artigo tem por objetivo discutir o modo como a indústria cultural retrata a figura feminina. Em tais representações percebe-se, muitas vezes, uma conotação sexual que desvaloriza a mulher, associando-a a satisfação dos desejos masculinos. A presente discussão desenvolveu-se a partir do método histórico-dedutivo, realizando uma revisão bibliográfica e documental do tema abordado. Verifica-se que a indústria cultural de massa como meio de enriquecimento e diversão, prioriza seus lucros e vendas, muitas vezes, utiliza a imagem feminina de maneira pejorativa. Assim, compreende-se a importância de se levantar tal discussão, buscando uma conscientização da indústria cultural quanto aos direitos humanos, inferindo que tal postura é uma violência que induz à discriminação.

\section{PALAVRAS-CHAVE}

Mulheres. Violência. Indústria Cultural. Direitos Humanos. 


\section{ABSTRACT}

This article aims to discuss how the cultural industry portrays the female figure. In such representations is often perceived a sexual connotation that devalues the women, linking her to the satisfaction of male desires. This discussion evolved from the historical-deductive method, conducting a literature review and documentary of the subject. It is found the culture industry as a means of enriching and fun, by prioritizing their profits and sales, often uses the feminine image in a pejorative manner. Thus, we understand the importance of raising this discussion, seeking cultural industry awareness about human rights, implying that such a stance is a Violence that leads to discrimination.

\section{KEYWORDS}

Women. Violence. Cultural Industry. Human Rights.

\section{RESUMEN}

Este artículo tiene como objetivo analizar cómo la industria cultural representa la figura femenina. En estas representaciones se percibe, a menudo una connotación sexual que evalúa las mujeres, vinculándola a la satisfacción de los deseos masculinos. Esta discusión se desarrolló del método histórico-deductivo, la realización de una revisión bibliográfica y documental sobre el tema. Se encontró que la industria de la cultura de masas como un medio de enriquecimiento y diversión, dando prioridad a las ganancias, a menudo usando la imagen femenina de una manera peyorativa. Por lo tanto, entendemos la importancia de aumentar ese debate, en busca de una conciencia de la industria cultural sobre los derechos humanos, lo que implica que esta postura es una violencia que conduce a la discriminación.

\section{PALABRAS CLAVE}

Mujeres. Violencia. Industria Cultural. Derechos Humanos.

\section{INTRODUÇ̃̃O}

0 presente artigo tem por objetivo analisar de forma crítica os discursos propagados pela mídia e pela Indústria cultural, segundo os quais a mulher é caracterizada única e exclusivamente como um objeto, responsável pela satisfação pessoal do homem. A Indústria cultural não apenas reproduz um discurso patriarcalista e antiquado, como, também, permite que as massas recebam tais mensagens de forma acrítica, visando uma permanência do status quo ${ }^{3}$.

3 Expressão latina que se refere ao estado atual de coisas ou situações. Origina-se do termo in statu quo ante bellum, cujo significado é "no estado (em que se estava) antes da guerra".
Como formadora de opinião, a indústria cultural influência a propagação de certos estereótipos femininos, que contribuem para disseminação do preconceito e da discriminação. Partindo do pressuposto de que certas exposições midiáticas - como comerciais, programas televisivos, filmes e músicas - são contrárias às lutas feministas por igualdade de gênero, promoção dos direitos humanos e direito a uma vida sem opressão, pretende-se demonstrar, ao longo deste trabalho, a presença de um tipo peculiar de violência na mídia: a violência simbólica de gênero. 
Considerando que a revisão literária auxilia na interpretação, compreensão e discussão do problema que foi proposto e corrobora para a elaboração de uma descrição sobre o tema, realizam-se pesquisas em obras bibliográficas e estudos já divulgados, que fornecem dados sobre o assunto,

A escolha deste tema justifica-se porque a reprodução da imagem feminina como um simples objeto de desejo fere os direitos humanos universais, além de possibilitar a propagação de ideias machistas, que conduzem até mesmo à própria violência física. Numa época em que o entretenimento midiático é defendido como se fosse um direito natural do homem, faz-se necessário se atentar para a situação da representação feminina na mídia. Sobretudo, quando transmite e perpetua a violência simbólica de gênero, trabalhando em favor da manutenção do status quo dessa sociedade opressora e contra o exercício da dimensão crítica da razão humana (PEREIRA NETO; LOIOLA; QUIXIDÁ; 2010).

Para elaboração deste artigo utiliza-se o método histórico-dedutivo. A pesquisa é do tipo revisão bibliográfica com base na pesquisa de dados secundários, sendo uma análise, essencialmente, bibliográfica e documental.

Utilizou-se a pesquisa bibliográfica em dados primários (dados de pesquisas originais e textos de leis) e secundários (dados de pesquisas originais coletados por outros autores), pois, conforme Cervo e Bervian (1996, p. 48 apud Gonçalves, Silva e Rodrigues, 2011, p. 12), "[...] a pesquisa bibliográfica é meio de formação por excelência. Como trabalho científico original, constitui a pesquisa propriamente dita na área das Ciências Humanas". Devido ao caráter de pesquisa bibliográfica e revisão de literatura, os dados primários e secundários foram coletados em diversas obras pertinentes ao tema.

No primeiro tópico apresenta-se o conceito de indústria cultural; para tanto, recorre-se aos textos traduzidos de Marcuse, Adorno e Hockeimer, autores da Escola de Frankfurt4. Em um segundo momento, busca-se desenvolver uma análise sobre o gênero e a violência simbólica de gênero, presentes nos meios de comunicação de massas. Posteriormente, será demonstrado que esse tipo de violência fere os Direitos Humanos Femininos Universais. Para legitimar tal assertiva, destacar-se-á dois tratados internacionais dos quais o Brasil é signatário: A Convenção Sobre a Eliminação de Todas as Formas de Discriminação Contra a Mulher e A Convenção Interamericana para Prevenir, Punir e Erradicar a Violência Contra a Mulher. Por fim, na conclusão, verificar-se-á que o Direito constitui poderosa arma no que tange à luta contra a violência simbólica de gênero.

\section{A INDÚSTRIA CULTURAL}

Os meios de comunicação de massa consolidaram-se como verdadeiros formadores de opinião, por meio do entretenimento, da informação e da propagação da cultura produzida, influenciam as relações dos indivíduos com o mundo e entre si mesmos. Diariamente, os indivíduos absorvem os mais diversos tipos de mensagens propagadas por esses meios - mensagens que, na maioria das vezes, são recebidas de forma acrítica. Questionando essa passividade social, os teóricos da Escola de Frankfurt demonstraram que tais

4 Escola de teoria social vinculada ao Instituto para Pesquisa Social da Universidade de Frankfurt, Alemanha. Foi composta por pensadores neo-marxistas, que teciam críticas tanto ao capitalismo quanto ao socialismo. Estudaram a questão da Cultura, analisando a transformação desta em simples mercadoria. 
mecanismos contribuem de forma significativa para a manutenção do status quo, uma vez que os produtos comercializados por meio dos meios de comunicação de massa obstam a emergência de um pensamento crítico, contestador e ativista (PEREIRA NETO; LOIOLA; QUIXANDÁ; 2010).

Para compreender a crítica realizada pelos frankfurtianos, faz-se necessário esclarecer a concepção destes sobre o termo cultura. Segundo Renato Ortiz (s.d.),

Quando os frankfurtianos se referem à cultura, eles utilizam o termo com um significado distinto do que lhe é conferido pelos antropólogos. Cultura não significa práticas, hábitos ou modo de vida, e se por um acaso é legítimo falarmos em antropologia, trata-se de uma Antropologia Filosófica. Na verdade os autores seguem a tradição alemã que associa cultura à Kultur, e a identificam com a arte, filosofia, literatura e música. As artes expressariam valores que constituem o pano de fundo de uma sociedade.

Marcuse (1986) compreende a cultura como "o conjunto de fins morais, estéticos e intelectuais que uma sociedade considera como objetivo de organização, da divisão e da direção do trabalho“. Ao se analisar os objetivos explícitos da civilização ocidental bem como sua pretensão de implementá-los, ver-se que a cultura pode ser compreendida como um processo de humanização,

caracterizado pelo esforço coletivo de proteger a vida humana, por apaziguar a luta pela existência mantendo-a dentro de limites aceitáveis, por estabilizar uma organização produtiva da sociedade, por desenvolver as capacidades intelectuais do homem e por reduzir as agressões, a violência e a miséria ${ }^{5}$ (tradução nossa) (MARCUSE, 1986, p. 56).

Contrapondo-se à ideia de cultura, estaria a civilização. Enquanto a primeira refere-se ao âmbito espiritual do indivíduo, a segunda relaciona-se com o âmbito material - ou seja, expõe o indivíduo a condições e

5 "Caracterizado por el esfuerzo colectivo por proteger la vida humana, por apaciguar la lucha por la existencia manteniéndola dentro de límites gobernables, por estabilizar una organización productiva de la sociedad, por desarrollar las facultades intelectuales del hombre, y por reducir y sublimar las agresiones, la violencia y la miseria" (MARCUSE,1986, p.56). necessidades externas, relacionadas ao trabalho, e ao comportamento social necessário (MARCUSE, 1986).

Dessa forma, a cultura burguesa defenderia a espiritualização do ser humano, sendo as funcionalidades do mundo material, ignoradas. Tais benefícios, entretanto, eram usufruídos apenas pela elite. Com o surgimento do capitalismo, a cultura foi transformada em bem de consumo para as massas com intuito não de democratizar as artes em meio à população oprimida, mas como forma de obtenção de lucro.

Como consequência, deu-se a perda do caráter livre e criativo da cultura burguesa, trazendo-a ao plano material utilitarista. A cultura passa, então, a possuir um caráter econômico - mera mercadoria, para ser vendida e consumida. Com a perda de grande parte de sua criatividade, a cultura contribuiu, ainda, para a formação de uma sociedade acrítica "pois a sua produção visa não ao esclarecimento dos indivíduos, mas sim prendê-los mais eficazmente à sociedade estabelecida na medida em que privilegia a diversão e o entretenimento em detrimento da formação crítica” (PEREIRA NETO; LOIOLA; QUIXANDÁ, 2010, p. 3).

Segundo Adorno e Hockheimer (1985), a cultura torna-se industrializada e obedece a certos padrões de produção. Tais padrões "teriam resultado originariamente das necessidades dos consumidores: eis por que são aceitos sem resistência" (ADORNO; HOCKEIMER, 1985, p. 57).

Os meios de comunicação transformam os indivíduos em telespectadores e ouvintes, tratando-os como verdadeira massa igual e uniforme. Assim, tais indivíduos são entregues a programas e canções padronizados, pré-fabricados, que inibem o pensamento crítico e massificam a sociedade. A Cultura passa a ser controlada, de forma que a "espontaneidade no público é dirigido e absorvido, numa seleção profissional, por caçadores de talentos, competições diante do microfone e toda espécie de programas patrocinados" (ADORNO; HOCKEIMER, 1985, p. 57). 
O novo e o espontâneo são completamente tolhidos pela indústria cultural. O novo, devido a seu caráter arriscado, experimental, o que conduz a possibilidade de perdas monetárias. 0 espontâneo, devido à inexistência de espaço para seu cultivo, sendo que o processo técnico tem como objetivo único à maximização dos lucros. "A máquina gira sem sair do lugar. Ao mesmo tempo em que já determina o consumo, ela descarta o que ainda não foi experimentado porque é um risco" (ADORNO; HOCKHEIMER, 1985, p. 63). A indústria cultural elege a padronização e a exploração de esquemas como forma de garantir o máximo de lucratividade.

A cultura produzida para o consumo das massas realiza um papel crucial no que tange ao conformismo social. Fora do trabalho, as massas consumem este tipo de cultura visando expurgar o espírito, recompondo-se, assim, para uma nova jornada de trabalho. Entretanto, a indústria cultural, como salientado, não estimula o pensamento crítico - antes o contrário; afasta a mente dos cidadãos explorados das questões capazes de fazê-los reagir contra a manutenção do status quo, tornando-os mais que meros expectadores, reprodutores de um sistema opressor e desigual, à medida que o aceitam passivamente (PEREIRA NETO; LOIOLA; QUIXANDÁ, 2010).

A cultura voltada para a maximização dos lucros forma um sistema orgânico. Cada setor - televisivo, musical, cinematográfico - compõe um sistema, que possui coerência, enquanto setor individual e man- tém essa coerência em conjunto. Isso demonstra a submissão e comprometimento dos meios de comunicação de massa e a cultura produzida por eles com o projeto de manutenção da sociedade capitalista. Por esse motivo, os frankfurtianos adotam o termo "indústria cultural”, “pois a expressão cultura de massa parece indicar uma cultura produzida ou até mesmo solicitada conscientemente pelas massas" (PEREIRA NETO; LOIOLA; QUIXANDÁ, 2010, p. 4).

Atualmente, percebe-se que a indústria cultural atua a pleno vapor. São diversos filmes, programas televisivos, músicas e demais formas de entretenimentos produzidos não como pura expressão da arte, mas como verdadeiros objetos a serem consumidos acriticamente. Antes da qualidade, a quantidade é colocada em primeiro plano - quanto mais se vende, mais se lucra. Os grandes produtores não se preocupam com os valores transmitidos através da chamada "arte”.

Dessa forma, faz-se extremamente necessário analisar os impactos causados por esta Indústria Cultural que, como formadora de opinião e produtora de modismos, interfere positiva e negativamente nas relações sociais. Conforme já aponta-se, far-se-á uma análise de como a Indústria Cultural auxilia na reprodução de estereótipos no que tange ao papel da mulher - estereótipos esses que, por sua vez, ferem os Direitos Humanos inalienáveis, propagando a violência simbólica de gênero.

\section{A VIOLÊNCIA SIMBÓLICA DE GÊNERO}

Para identificar o conceito de violência simbólica de gênero, faz-se necessário esclarecer o próprio conceito de gênero. Segundo Scott (1995), diz respeito ao elemento que constitui as relações sociais baseadas sobre as diferenças percebidas, e implicam em quatro aspectos: 1) símbolos culturalmente disponíveis que evocam representações simbólicas; 2) conceitos normativos que põem em evidência as interpretações do sentido dos símbolos expressos nas doutrinas religiosas, educativas, políticas e cientificas; 3 ) instituições e organização social; e 4) a identidade subjetiva ${ }^{6}$.

6 Dentro dessas quatro dimensões que se intercruzam, analisaremos a dimensão institucional - a mídia - que reitera através dos seus discursos as desigualdades de gênero, contrapondo-se diretamente a direitos humanos universais. 
Desse modo, pode-se compreender o gênero como um conjunto de códigos manipulados, de costumes, que se corporificam. São as relações de poder, entre homem e mulher que vão se desenvolver a partir daí, já que segundo afirmativa de Klapisch-Zuber (1990, p.17) "Nascer homem ou mulher não é, em nenhuma sociedade, um dado biológico neutro, uma simples qualificação 'natural' que permaneça como que inerte". Diferentemente do sexo, ditado pela biologia e estabelecido logo ao nascimento, o gênero é uma construção social, em que mulheres devem incorporar certos padrões aceitáveis e os homens, outros.

Temos que nos submeter a determinados rituais, muitas vezes diários, para nos tornarmos mulheres (ou homens) segundo os ditames da sociedade em que vivemos e, assim, definirmos, aos nossos olhos e aos dos outros, a nossa identidade de gênero. E tudo isso, é ló gico, acompanhando os padrões vigentes de estética, impostos aos respectivos gêneros, padrões esses que variam no tempo e no espaço, tanto geográfico quanto social (SARDENBERG, 2002, p. 59).

Esclarecido o conceito de gênero, pode-se apreender que a violência simbólica de gênero é entendida como "constrangimentos morais impostos pelas representações sociais de gênero - sobre o masculino e o feminino" (Cruz, 2008, p. 4). Apesar dos diversos direitos humanos atribuídos às mulheres, o preconceito oriundo da ordem patriarcal que ainda impera na sociedade, de forma velada ou explícita, permite a constante disseminação de "piadas, canções, comerciais, filmes, novelas, etc." (Cruz, 2008, p. 4) degradantes e constrangedoras para o gênero feminino. Apesar das notórias conquistas no que se refere à igualdade formal, e a diversos direitos positivados, a figura da mulher como objeto ainda impera; basta ligar nossos televisores para vislumbrar este fenômeno patrocinado pela indústria cultural, que nos torna telespectadores acríticos.

São imagens “jogadas” para os telespectadores, que assumem uma visão passiva da problemática em questão. A discussão "passiva" do telespectador diz respeito à falta de tempo para traduzir, processar e interpretar a quantidade de imagens emitidas pela televisão. Assim, as imagens transmitidas pelos meios de comunicação como televisão, jornais e revistas reproduzem representações de mulheres modernas, dinâmicas, independentes... e "coisificadas" (CRUZ, 2008, p. 4).

A opressão feminina passou a adquirir novos contornos, veiculada como forma de entretenimento - 0 que retira seu caráter sério e capta o apoio da população acrítica. De forma quase imperceptível, a indústria cultural consegue estabelecer seus moldes para as mulheres da modernidade, que aceitam tais imposições sem maiores questionamentos. Tal fato auxilia de forma crucial na propagação de preconceito e discriminação, legitimando o pensamento patriarcal ainda existente e calando as vozes das chamadas "feministas barulhentas." Em uma análise da representação feminina nas propagandas de cerveja veiculadas pela mídia, Cruz (2008, p. 5) afirma que

as práticas discursivas produzidas pela mídia, são formas simbólicas, que veiculam noções existentes na sociedade, reproduzindo crenças, valores e identidades sociais, retratando alterações históricas, e contribuindo para a perpetuação ou transformação das relações sociais. os contextos sociais são constitutivos da produção das formas simbólicas, e dos modos pelos quais essas formas são recebidas e entendidas, contribuindo também para as maneiras pelo qual elas serão interpretadas, recebidas e valorizadas. Dentro dessa perspectiva, as propagandas que analiso são formas simbólicas produzidas pela mídia. Nessas propagandas existem representações que são construídas e transmitidas que legitimam a ideologia dominante. Desde modo, alguns grupos sociais têm os seus símbolos e significados representados em detrimento de outros grupos.

As representações midiáticas refletem padrões estabelecidos na sociedade, perpetuando estereótipos dos modelos femininos. Tais estereótipos são aceitos acriticamente pelos receptores, que não veem necessidade de contrapô-los, pois são baseados no próprio senso comum. Ademais, essas representações são vistas como reais e naturais; fenômeno denominado por Thompson (1995) de "reificação": uma estratégia para a permanência de determinadas normas, valores e posturas como elementos contemporâneos, justamente por serem consideradas pertencentes a uma tradição 
“eterna” e, por esta razão, aceita e justificável, em que uma situação transitória é representada como permanente, ocultando seu caráter sócio-histórico.

A mídia constrói o estereótipo feminino pautado nas imagens e mitos contemporâneos. Assim, a imagem da mulher é criada, aceita e partilhada socialmente por um grupo de pessoas que se identificam com esta imagem - mesmo que fira direitos fundamentais.

Cabe destacar o papel crucial de certos gêneros musicais no que se refere à perpetuação da violência contra a mulher, em toda sua amplitude. Segundo Feitosa, Lima e Medeiros (2010, p. 4):

A violência constitui o instrumento mais antigo de expressão do poder do homem, e está presente na vida de milhões de mulheres de todas as classes socais, raças/etnias e orientação sexual. É por meio desse instrumento que o mundo masculino impõe sua dominação no momento em que as mulheres ousam contrariar o papel a elas reservado. As diferentes práticas de violência contra as mulheres, como a física, a simbólica, sexual, patrimonial, foram naturalizadas no seio da sociedade e se fazem presentes tanto nos espaços de intimidade como no espaço público.

A naturalização de condutas violentas, por exemplo, é refletida nas letras de músicas de certas canções. Uma vez que a indústria musical faz parte da indústria cultural, notável produtora de lixo propositalmente fabricado (ADORNO; HOCKEIMER, 1985), pode-se inferir que tais ideologias influenciam seus ouvintes, de forma a manter e perpetuar o status quo patriarcal. Feitosa, Lima e Medeiros (2010, p. 4) analisam uma letra do gênero musical "forró estilizado":

As letras das músicas do forró estilizado trazem essa naturalização. Nelas, a violência contra as mulheres é tratada, muitas vezes, como instrumento que dá prazer às mulheres, alimentando, assim, o mito de que "mulher gosta mesmo é de apanhar", a exemplo da letra da música Tapa na Cara: Ela é safada, mas gosta de apanhar. E diz que é gostoso na hora de amar. Apanha pra dormir, apanha pra acordar. Apanha todo dia, toda hora sem parar. Eu sei o que fazer pra ela não brigar. É tudo diferente, seu remédio é apanhar [...]. O povo na minha rua já tá desconfiando. Pensando que eu bato com ciúme da mulher. Todo mundo pensa que eu sou um mau marido. Mas só que eles não sabem a cachorra que ela é...

0 mesmo ocorre no gênero musical conhecido como "funk carioca." Nesse tipo de música, a mulher é interessante apenas se estiver disposta a assumir o papel de objeto sexual, subordinada aos homens para que estes possam satisfazer sua lascívia pessoal. Dentro do contexto social do funk, ou seja, em meio a seus ouvintes, tais papéis são aceitos e mesmo aclamados, tanto pelas mulheres que se sujeitam a um tratamento degradante, quanto pelos homens (ARAGÃO, 2011). É importante ressaltar que não se critica aqui o gosto pessoal do indivíduo, mas sua incapacidade de pensar criticamente sobre suas ações, fruto da manipulação oriunda da indústria cultural. Em relação às letras do funk carioca, Aragão (2011, p. 81) comenta:

É possível ver como, por meio da linguagem, as formações ideológicas e discursivas de sujeitos que repetem o já-dito de que a mulher está submissa ao homem, "Fico tarado/Quando vejo o rebolado dessa mina". Vejamos também uma autoria feminina, que representa discursos de mulheres que aceitam sua submissão sexual, "Sou cachorra, sou gatinha/Não adianta se esquivar/Vou soltar a minha fera/Eu boto o bicho pra pegar". Há em outras músicas outras representações de tais formações ideológicas e discursivas, através da linguagem nos textos, que o universo feminino é aproveitado principalmente e apenas sexualmente, até mesmo vulgarmente.

Diversos outros exemplos são fáceis de serem encontrados na música brasileira atual. Nas músicas que reproduzem a ideologia machista, pode-se encontrar basicamente o desrespeito à condição da mulher; a violação dos diversos direitos e garantias fundamentais em âmbito nacional e internacional e, infelizmente, a desvalorização da luta histórica protagonizada pelos movimentos feministas que, aos poucos, tentaram inserir a mulher na sociedade, valorizando-as como ser humano e não como mero objeto. 


\section{OS DIREITOS HUMANOS DAS MULHERES}

Pode-se afirmar que os direitos humanos "São poderes aparados pela comunidade, que geram condutas obrigatórias para os demais, e dos quais se é titular pelo simples fato de ser um membro da espécie homo sapiens sapiens" (RABINOVICH, 2007).

São direitos especiais, dotados de características particulares. São universais, pois são aplicáveis a qualquer pessoa, se estendendo a toda cultura humana; são indisponíveis, pois não se pode renunciar à própria dignidade humana; proíbe o retrocesso, pois uma proteção conquistada jamais poderá ser retirada; inalienáveis, não podem ser transferidos; imprescritíveis, por não serem perdidos com o passar do tempo; invioláveis, porque não podem ser atingidos por agentes públicos ou leis infraconstitucionais ${ }^{7}$ e ainda, são dotados de efetividade, pois o Poder Público deve garantir sua aplicabilidade no mundo dos fatos (LAVORENTI, 2009).

Diversas foram as discussões sobre os direitos humanos das mulheres - discussões essas tratadas em conferências, culminadas em declarações e planos de ação. Para efeitos deste estudo, entretanto, abordar-se-á dois dos principais tratados ${ }^{8}$ sobre direitos femininos: a Convenção sobre Eliminação de Todas as Formas de Discriminação contra a Mulher, em âmbito global, e a Convenção Interamericana para Prevenir, Punir e Erradicar a Violência Contra a Mulher, em âmbito regional.

O sistema internacional de proteção dos direitos humanos é constituído por duas esferas: a esfera global, formada pela ONU, e a esfera regional, constituída, no caso brasileiro, pela Organização dos Estados Americanos - OEA. Tais sistemas, e seus respectivos instrumentos específicos (...) são complementares, pelo que coexistem com o propósito de salvaguardar os mesmos direitos, objetivando a máxima eficácia na tutela de proteção aos direitos humanos (LUCK, 2010, p. 2).

7 Entende-se por infraconstitucional toda e qualquer lei hierarquicamente inferior à Constituição Federal - tal qual os Códigos, Leis Complementares, Portarias, etc...

8 É importante ressaltar que os tratados internacionais são passíveis de aplicação apenas aos Estados signatários.
No tópico que se segue, analisaremos a Convenção sobre Eliminação de Todas as Formas de Discriminação contra a Mulher.

\section{1 CONVENC̣̃̃O SOBRE ELIMINAÇÃO DE TODAS AS FORMAS DE DISCRIMINAÇÃO CONTRA A MULHER}

Adotada pela Organização das Nações Unidas em 18 de dezembro de 1979 e assinada pelo Brasil na mesma data, a Convenção compõe-se de um preâmbulo ${ }^{9}$ e 30 artigos, divididos em seis partes. São elas: disposições gerais (arts. $1^{\circ}$ ao $6^{\circ}$ ); direitos políticos (arts. $7^{\circ}$ a $9^{\circ}$ ); direitos econômicos e sociais (arts. 10 a 14); direito à igualdade (arts. 15 e 16); implementação da Convenção (arts. 17 ao 22) e disposições regulamentares (arts. 23 ao 30).

O preâmbulo desta Convenção (1979) acentua que a igualdade entre homem e mulher só será alcançada quando o tradicional papel de ambos na sociedade e na família for alterado - ou seja, refere-se diretamente à questão do gênero (LAVORENTI, 2009). Assim, pode-se afirmar que a violência simbólica de gênero contribui para a permanência dos tradicionais papéis sociais discriminadores que obstam a busca por uma igualdade de gênero.

No que alude à discriminação, a Convenção (1979) define em seu artigo $1^{\circ}$ como

[...] toda a distinção, exclusão ou restrição baseada no sexo e que tenha por objeto ou resultado prejudicar ou anular o reconhecimento, gozo ou exercício pela mulher, independentemente de seu estado civil, com base na igualdade do homem e da mulher, dos direitos humanos e liberdades fundamentais nos campos político, econômico, social, cultural e civil ou em qualquer outro campo.

A violência simbólica de gênero realiza uma distinção baseada no gênero e no papel social do homem e da mulher, de forma a resultar em prejuízo sociocultural para a figura feminina como um todo. Assim

9 Justificativa do porquê da elaboração do tratado. O preâmbulo indica as partes contratantes (os Estados ou as organizações internacionais que concluem o tratado) com a menção das credenciais dos representantes dos Estados (LAVORENTI, 2009). 
sendo, infere-se que essa violência pratica e induz à discriminação, visto ser veiculada pela mídia, que é uma formadora de opinião. A discriminação só é reconhecida como tal se feita com base no sexo e tiver por objetivo prejudicar ou mesmo anular o reconhecimento, gozo ou exercício pela mulher dos direitos humanos em diversos campos, inclusive o social e cultural (LAVORENTI, 2009).

A Convenção possui duas vertentes: a) repressivo-punitiva, como forma de suprimir a discriminação; b) positivo-promocional, que visa promover a igualdade. Por meio disso, os Estados são coagidos a adotar medidas que visem eliminar a discriminação, adotando princípios igualitários em suas leis internas e evitando que seus agentes pratiquem condutas discriminatórias.

De acordo com o artigo $2^{\circ}$ da Convenção, o Estado signatário, também, é obrigado a realizar medidas que visem eliminar posturas discriminatórias por organizações e empresas. Sendo que em sentido jurídico empresa é sinônimo de atividade econômica, verifica-se, então, que o Estado deve coibir a propagação de ideologias patriarcais discriminatórias por parte da indústria cultural:

Atenta à criação histórica e cultural dos papéis que submeteram as mulheres à dominação e exploração masculinas, a Convenção pugna para que haja o comprometimento dos Estados-Partes de modificar os padrões socioculturais que conduzem ao preconceito pelo entendimento de inferioridade ou superioridade de qualquer dos sexos ou com base em funções estereotipadas de homens e de mulheres (LAVORENTI, 2009, p. 57).

Apesar da Convenção assim dispor, percebe-se na rotina diária que, ao invés de suprimidos, tais padrões socioculturais são reverenciados como arte, enquanto produtos da indústria cultural.

A fim de avaliar a execução da Convenção pelos Estados-membros, as Nações Unidas criaram no texto da Convenção (1979), em seu art. 17, um Comitê sobre a Eliminação da Discriminação contra a Mulher. Por esta Convenção, os Estados-Partes comprometeram-se a submeter ao Secretário Geral das Nações Unidas um Relatório que evidencie o modo pelo qual está implementando a Convenção e que medidas estão sendo seguidas para tornar efetivo o seu conteúdo.

A cada quatro anos esse Relatório deverá ser atualizado e, mais uma vez, apresentado para exame do Comitê. Além disso, há um Protocolo Opcional à Convenção sobre a Eliminação de todas as formas de Discriminação contra a Mulher, que estabelece dois mecanismos de monitoramento, quais sejam: o mecanismo da petição, que permite o encaminhamento de denúncias de violação de direitos enunciados na Convenção à apreciação do Comitê sobre a Eliminação da Discriminação contra a Mulher; e um procedimento investigativo que habilita o Comitê a averiguar a existência de grave e sistemática violação aos direitos humanos das mulheres.

\subsection{CONVENCÕ̃O INTERAMERICANA PARA PREVENIR, PUNIR E ERRADICAR A VIOLEENCIA CONTRA A MULHER}

A Convenção Interamericana para Prevenir, Punir e Erradicar a Violência contra a Mulher, também conhecida como Convenção de Belém do Pará, foi promulgada em solo brasileiro em $1^{\circ}$ de agosto de 1996.

Constituindo verdadeiro avanço no que tange à proteção internacional dos direitos das mulheres, a Convenção de Belém do Pará não apenas reconhece que a violência transcende os setores sociais, como também reconhece "que a violência ofende a dignidade humana e revela uma manifestação de relação de poder historicamente desigual entre homens e mulheres" (LAVORENTI, 2009, p. 86).

Para efeitos da Convenção, entende-se por violência "qualquer ato ou conduta baseada no gênero, que cause morte, dano ou sofrimento físico, sexual ou psicológico à mulher, tanto na esfera pública como na esfera privada" (AGENDE, 2004, p. 9). Em relação ao sofrimento psicológico, cabe salientar a chamada violência moral. 
A violência moral é uma das manifestações da violência psicológica. Consiste em acusações que atingem a reputação da mulher. É comum nesses casos que a ofensa sofrida se relacione ao exercício da sexualidade pela mulher, tratando este exercício como algo reprovável e sujo (AGENDE, 2004). Percebe-se que a violência moral relaciona-se com a violência simbólica de gênero, denigrindo a imagem da figura feminina a partir de ofensas contra a honra e a reputação da mulher em geral.

A Convenção (1994) elenca, em seu artigo $4^{\circ}$, diversos direitos que devem ser garantidos às mulheres como forma de evitar a violência e a discriminação. Dentre eles, cabe salientar o direito ao respeito de sua incolumidade física, psíquica e moral e o respeito à sua dignidade - ambos ignorados pela indústria cultural ao propagar a violência simbólica de gênero. Segundo Lavorenti (2009, p. 92):

\section{CONSIDERACC̄ẼES FINAIS}

Utilizando os embasamentos teóricos dos autores da escola de Frankfurt, identifica-se não apenas a origem da desconstrução da cultura enquanto arte, como também os objetivos desta verdadeira indústria capitalista. Uma vez cientes de que tal indústria contribui de forma crucial para a passividade social e para a manutenção da ordem patriarcal que ainda impera em nossa sociedade, infere-se que o despertar do senso crítico seria uma poderosa arma na luta pela efetivação da igualdade de gênero.

Segundo Cruz (2008), o movimento feminista, junto com alguns setores da sociedade desenvolvem um trabalho de conscientização e crítica em relação à forma como a imagem da mulher vem sendo abordada na mídia. Leis estão sendo implementadas para que se proíba a veiculação de propagandas de cunho
Do fato de a violência da mulher ter por base a questão do gênero, conforme definição dada pela própria Convenção, decorre que o direito a uma vida livre dessa violência conduz ao direito de a mulher ser valorizada e de ver erradicados padrões estereotipados de comportamento socioculturais com supedâneo em conceitos de inferioridade e subordinação. Esse caldo cultural é que fomenta a discriminação, que, por sua vez, propicia e facilita a prática da violência.

De forma a fiscalizar a implementação da Convenção (1994), os arts. 10,11 e 12 estabelecem a necessidade de Relatórios nacionais enviados pelos Estados à Comissão Interamericana de Mulheres com informações sobre as medidas adotadas, as dificuldades enfrentadas na aplicação das mesmas e os fatores que contribuam para a violência contra a mulher (art.10). O sistema de Petições individuais, também, está presente, estabelecido no artigo 12 do referido diploma legal.

erótico. Por exemplo, o Projeto de Lei n 11/2003 da Deputada lara Bernardi (PT-SP), limitando a veiculação de propagandas que utilizem imagens sensuais ou pornográficas nos meios de comunicação do País.

Porém, sabe-se que leis como esta atingem diretamente os interesses dos grandes publicitários e empresários televisivos, detentores de poder aquisitivo, capazes, portanto, de interferir em qualquer tempo contra este tipo de "empecilho". Ademais, se deve lembrar que o senso comum que impera na sociedade já está contaminado pelos estereótipos midiáticos - as pessoas já incorporaram a crença de que tais padrões são perfeitamente normais e aceitáveis, sendo que romper com isso de maneira brusca é algo delicado; ninguém irá apoiar uma causa "de feminista mal-amada”. 
Apesar de todas as dificuldades citadas, medidas alternativas podem ser realizadas. 0 Direito, que por vezes é utilizado como legitimador de atrocidades, ainda oferece égide aos hipossuficientes - seja pelos seus princípios gerais, seja pelas normas universais dos direitos humanos. Destarte, para proteger, garantir e efetivar uma situação de dignidade para as mulheres, historicamente reprimidas, faz-se mister compreender, estudar e aplicar as normas jurídicas que as favorecem.
O jurista, neste caso, deve atuar de forma zelosa. Sabe-se que existe uma grande discrepância entre o que se escreve na lei e o que se aplica ao mundo dos fatos. Contudo, a possibilidade de recorrer a medidas internacionais, com o intuito de efetivar direitos e garantias básicas a qualquer ser humano, lança luz em meio a esta obscura batalha.

\section{REFERÊNCIAS}

ADORNO, Theodor; HORKHEIMER, Max. Dialética do Esclarecimento. Trad. Guido Antonio de Almeida. Rio de Janeiro: Jorge Zahar, 1985.

AGENDE. Ações em Gênero, Cidadania e Desenvolvimento. 10 anos da adoção da Convenção Interamericana para Prevenir, Punir e Erradicar a Violência contra a Mulher. Convenção de Belém do Pará. Brasília: AGENDE, 2004, 36 p.

ARAGÃO, Gabriel Adams Castelo Branco de. 0 discurso e a construção da imagem feminina no FUNK. In: Cadernos de Pesquisa de Graduação em Letras. Uberaba. 2011. Disponível em: <uftm.edu.br/revistaeletronica/index.php/cpgl/article/download/124/152>. Acesso em: 16 set. 2011.

BLOCH, R. H. Misoginia Medieval e a invenção do amor. Rio de Janeiro: 34, 1995.

CONVENÇÃo sobre a Eliminação de Todas as Formas de Discriminação Contra as Mulheres. 18 dezembro 1979. Disponível em: < http://www.pge.sp.gov.br/ centrodeestudos/bibliotecavirtual/instrumentos/discrimulher.htm>. Acesso em: 16 set. 2011.

CONVENÇÃO interamericana para prevenir, punir e erradicar a violência contra a mulher (Convenção de
Belém do Pará). 9 junho 1994. Disponível em: < http:// www.cidh.org/Basicos/Portugues/m.Belem.do.Para. htm>. Acesso em: 15 set. 2011.

CRUZ, Sabrina Uzêda. A representação da mulher na mídia: Um olhar feminista sobre as propagandas de cerveja. Revista Travessias. 4. ed. issn 1982-5935. Educação, Cultura, Linguageme Arte, 2008. Disponível em: < http://www.cult.ufba.br/enecult2008/14477. pdf >. Acesso em: 15 set. 2011.

DUBBY, Georges; PERROT, Michelle (org). História das Mulheres: A Idade Média. Porto: edições afrontamento, 1990.

FEITOSA, Sônia de Melo; LIMA, Marwyla Gomes de; MEDEIROS, Milena Gomes de. Patriarcado e forró: uma análise de gênero. In: Seminário Internacional Fazendo Gênero 9: Diásporas, Diversidades, Deslocamentos. Florianópolis, 2010.

GONÇALVES, Flávia de Luna Sousa; SILVA, Rosemary Aparecida; RODRIGUES, Liz Helena S. do Amaral. A Análise das características socioeconômicas das mulheres negras encarceradas. In: VII Congresso Brasileiro de Direito e Teoria Geral do Estado. Montes Claros, 2010. 
LAVORENTI, Wilson. Violência e Discriminação contra a Mulher: Tratados Internacionais de Proteção e o Direito Penal Brasileiro. Campinas: Millenium, 2009.

LUCK, Alan Saldanha. 0 sistema internacional de direitos humanos. In: Âmbito Jurídico, Rio Grande, 72, 01/01/2010 [Internet]. Disponível em <http://www.ambito-juridico. com.br/site/index.php?n_link=revista_artigos_ leitura\&artigo_id=7067>. Acesso em: 15 set. 2011.

MACEDO, José Rivair. A mulher na Idade Média. São Paulo: contexto, 2002.

MADUREIRA, Daniele. 0 papel social da propaganda. Disponível em: <www.abap.com.br, 22-04-2002>. Acesso em: 16 set. 2011.

MARCUSE, Herbert. Ensayos sobre política y cultura. Barcelona: PLANETA-AGOSTINI, 1986.

ORTIZ, Renato. A Escola de Frankfurt e a questão da cultura. Disponível em: <http://www.anpocs.org. br/portal/publicacoes/rbcs_00_01/rbcs01_05.htm>. Acesso em: 17 set. 2011.
PEREIRA NETO, Francisco Edmar; LOIOLA, Alex Lacerda Gomes; QUIXADÁ, Luciana Martins. Cultura e Irracionalidade: a barbárie dança no ritmo do forró. In: IV Colóquio Internacional Educação e Contemporaneidade. Laranjeiras. 2010.

RABINOVICH-BERKMAN, Ricardo D. Derechos Humanos. Buenos Aires: Quorum, 2007.

SARDENBERG, Cecília. A mulher frente à cultura da eterna juventude: reflexões teóricas e pessoais de uma feminista "cinquentona". In: FERREIRA, Silvia Lúcia. NASCIMENTO, Enilda Rosendo do. (org.). Imagens da mulher na cultura contemporânea. Salvador: NEIM/UFBA, 2002, p.51-68. (Coleção Bahianas, v. 7).

SCOTT, Joan. Gênero: uma categoria útil de análise histórica. In: Revista Educação e Realidade, v. 2, 20, jul/dez. Porto Alegre, 1995.

THOMPSON, John B. Ideologia e Cultura Moderna: Teoria social crítica na era dos meios de comunicação de massa. Petrópolis, Rio de Janeiro: Vozes, 1995. 